\title{
Techniques of Shifting Part of Speech in Biological English (ESP) Literature Translation
}

\author{
Xiujuan Wang1, Jilian $\mathrm{Hu}^{1}{ }^{*}$, Jie Pan ${ }^{2}$, Wenjing Wang ${ }^{2}$ \\ ${ }^{1}$ College of Economics and Management, Shandong Agricultural University, Tai'an Shandong \\ ${ }^{2}$ College of Foreign Languages, Shandong Agricultural University, Tai'an Shandong \\ Email: xjw9007@126.com, *jlhu@sdau.edu.cn
}

How to cite this paper: Wang, X. J., Hu, J. L., Pan, J., \& Wang, W. J. (2017). Techniques of Shifting Part of Speech in Biological English (ESP) Literature Translation. Open Journal of Modern Linguistics, 7, 53-64.

https://doi.org/10.4236/ojml.2017.72005

Received: February 1, 2017

Accepted: April 14, 2017

Published: April 17, 2017

Copyright $\odot 2017$ by authors and Scientific Research Publishing Inc. This work is licensed under the Creative Commons Attribution International License (CC BY 4.0).

http://creativecommons.org/licenses/by/4.0/

\begin{abstract}
Part of speech is a core concept of the traditional English grammar. The use of different kinds of parts of speech has strict rules. Because of the differences between source language and target language, simply translate mechanically will cause great negative impact on translation work, especially in literary translation. Therefore, we should jump out of the bondage of the original part of speech and shift the part of speech flexibly in order to achieve a vivid translation effect. Parts of speech shift are also called zero inflectional changes, or functional transformation. In contemporary English, parts of speech shift method are the most common means of word formation and very active grammatical rhetorical methods. As a language phenomenon, the shift of parts of speech is not only extremely common in literature translation work, but also very important as a way of word formation in biological and scientific work translation. However, parts of speech shift are not only a way of word-formation in traditional English grammar. This article will combine the emergence and development of cognitive linguistics to discuss the part of speech shift mechanism and skills from the perspective of human cognitive ability, and concludes several useful methods in contemporary translation work of biological papers.
\end{abstract}

\section{Keywords}

Part of Speech, Transformation,

Biological Literature English for Specific Purposes, Translation

\section{Introduction}

In grammar, a part of speech (also a word class, a lexical class, or a lexical category) is a linguistic category of words (or more precisely lexical items), which is generally defined by the syntactic or morphological behavior of the lexical item 
in question. Common linguistic categories include the noun and verb, among others (Bassnett, 1998). There are open word classes, which constantly acquire new members, and closed word classes, which acquire new members infrequently (Anderson \& Marchant, 2015). There is something in common in the vocabulary, grammar, structure and expression between English and Chinese, but they are also something different. In English-Chinese translation, in such circumstance which English sentences' vocabulary and expressive way is consistent or similar with Chinese sentences, we can adopt the method of "word for word" translation. While some other sentences cannot be translated in this way, otherwise, the translation is not accord with the Chinese habit of expression (Cai, 2012). During this time, we would then use part of speech transformation strategy to complete the translation (Caffarel, 2010). Considering the different characteristics between English and Chinese, strategies we can use mainly include convert adverbs into adjectives, nouns into verbs, prepositions as verbs, adjectives as verbs and so on.

Almost all languages have the lexical categories noun and verb, but beyond these there are significant variations in different languages (Cook, 2010; Gu, 2012; Gentzler, 2001). For example, Japanese has as many as three classes of adjectives where English has one; Chinese, Korean and Japanese have nominal classifiers whereas European languages do not; many languages do not have a distinction between adjectives and adverbs, adjectives and verbs or adjectives and nouns, etc. (Kong, 2012). This variation in the number of categories and their identifying properties entails that analysis to be done for each individual language. Nevertheless the labels for each category are assigned on the basis of universal criteria. In linguistics, shift also called zero derivation, which is a kind of word formation; specifically, it is the creation of a word (of a new word class) from an existing word (of a different word classes) without any change in form (Dancygier, 2012). For example, the noun green in golf (referring to a putting-green) is derived ultimately from the adjective green. Shifts from adjectives to nouns and vice versa are both very common and a notable English; much more remarked upon is the creation of a verb by converting a noun or other word (e.g. the adjective clean becomes the verb to clean).

The 21st century is the century of life science, the rapid development of biology and biotechnology boost the surge of biology literates (Nida, 2001; Shi, 2014). Biology literature translation belongs to the category of science and technology translation, this work usually follows the principle of "faithfulness, expressiveness and elegance", but as a technology translator, we must be accurate and smooth at first. According to the problems existed in the translation work of current biology field, and combined with some personal understanding, I concluded three characteristics of biological literature translation as follows. Meanwhile, biomedicine is becoming one of the most rapidly-developing disciplines among the natural science field (Snell-Hornby, 2006). Biomedical works are important documents which could elucidate, introduce and spread new discoveries, new ideas and new methods. English is the most commonly used language 
in biomedical works; even non-English works are often accompanied by corresponding English abstract. In China, biomedical English works. Biomedical works not only have scientific nature, advanced nature and practicability, they also have a certain degree of ideological level and literalness. Being different with Chinese biomedical works, it is common that English words have the phenomenon of polysemy. Some words in English biomedical works are endowed with new meaning, and are attached with additional information, and this phenomenon has become a difficulty in translation work, so the mastery of the correct meanings of these difficult words has been playing a very important role in improving the translation quality and grasping the original message (Sarceive, 1994). Due to the advantages of English in communication, the phenomenon of English terms appearing in Chinese papers without being translated is emerging in recent years, such as HIV, HPV, CELL which have long been used in China. At present, the main reasons for this kind of phenomenon are as follows. First, due to the popularity of English around the world, English has become the most common working language and communication tool. Second, new words surge so quickly in such an information age, people don't have enough time to give each team a translation which is both peer to peer and smart, what's more, using the originals can avoid misunderstandings. In social science and natural science, different translators have different usages on the same terms translation which can easily lead to confusion.

With the advent of the era of information, timely transmission and handling of information technology have become the key to the society's productivity, competitiveness and development. In terms of science and technology literature translation, traditional complete translation methods can no longer keep up with the development of the times. Meanwhile, a new kind of translation method-translation variation is showing its vitality. Translation variation method can assure the translator full play to creativity. It also allows the translator to adopt the method of expansion, trade-offs, complement, merger, quickly convey to scientific and technological personnel on those foreign and domestic information according to readers' demand, in order to improve the value of science and technology information. The outline of this research is as follows: Part two introduces the main ideas of parts of speech shift translation, part three discusses the bio-medical literature translation skills with some specific examples and part four is the conclusion of the whole article.

\section{Main Ideas of Parts of Speech Shift Translation}

\subsection{The Definition of Part of Speech Shifting}

In order to make translation work accurate and fluent, some certain parts of speech of the original need to be converted into another part of speech, such as English nouns into Chinese verbs, verbs in English translated into Chinese nouns, verbs in Chinese translated into English prepositions, etc. This is the part of speech transformation.

Modern translator Yan Fu once said: There are three fundamental principles 
for translation, faithfulness, expressiveness and elegance. The so-called "faithfulness" is faithful to the original. The word "expressiveness" refers to the easy understanding of the smoothly translated work and "elegant" refers to the beauty. Chinese and English are two different languages. Despite some similarities between them, there is still a striking difference in many aspects, such as the vocabulary, grammar, sentence structure, and culture, etc. Therefore, in the process of English-Chinese or Chinese-English translation, the translator should not only strive to be faithful, but also to make the translation in accordance with the habit of language expression, make the translation smooth, fluent and beautiful.

However, many people think that the biggest obstacle is supposed to be a different transformation of parts of speech between two kinds of languages. Because not all words in one language are able to find a same part of speech in another language while the meaning is exactly the same. Only by changing a certain part of speech of the original text can more effectively convey the precise meaning of the original.

\subsection{Parts of Speech Shift Mechanisms}

The mechanism of parts of speech shift is highlighted, metaphor and metonymy mapping. Parts of speech shift process have two stages, in the first stage, some knowledge of a particular event or situation get activated and highlighted due to its strong degree of significance. In the latter phase, activated and highlighted knowledge triggers conceptual metonymy and conceptual metaphors between two different domains (the original domain and the domain) in the same cognitive domain; and the understanding of the domain can be achieved via metonymy mapping and metaphorical mapping. Highlight in the process of word formation.

Parts of speech shift process start by highlighting our understanding of an event or situation from different aspects. The highlights of a transformation process are closely related to the process of construction or cognitive ability, that is to say, it is connected with our ability to conceive and describe things in different situations. More accurately, the scope of the relevant concepts, the selection of a specific scenario perspective, and the entity's degree of highlights all has great influence on the process of part of speech shift. For example, the following four sentences highlight our understanding of the animal wolf from different aspects.

1) We could often hear the wolves howling in the forest at night.

2) The job may not be very exciting, but the money will help to keep the wolf from the door.

3) Mr. Black was fooled by the salesman's manners until he showed that he was really a wolf in sheep's clothing, by selling Mr. Black a car that was falling apart.

4) That boy wolfed down the whole cake, while my back was turned!

In sentence one, we know about wolves as "a wild animal eating other ani- 
mals" and "a feeling of howling in the night". Even our formal relevant experience is highlighted. In sentence two, we see our cognitive process highlights "to earn money to survive" or some experience related to hunger. In sentence three, the image of "a seemingly friendly but dark heart person" got highlighted. Sentence four highlights the "eating behavior".

\subsubsection{Metonymy Mapping in the Process of Transformation}

Added and converses (1999) pointed out that the process of metonymy is actually a process of one entity to replace the other conceptual entity. In this process, a conceptual entity or carrier exists in the same ICM. For example, in the sentence "She mothered her plants as she does her children", the word "mother" can be seen as cognitive triggers or metaphors for domain ontology which provides psychological help on the domain of "she acted as a mother in taking care of the plant". Moreover, metonymy mapping is very important to the understanding of the parts of speech shift process, for example, "they wintered in America". To understand the above sentence, winter is regarded as a cognitive triggers, it inspired the metonymy of the concept time.

\subsubsection{The Change of Metaphorical Mapping}

Metaphorical mapping is obvious in the process of shift between nouns and verbs. According to what Langacker said, in cognitive linguistics, nouns tend to highlight things, while other words often highlight a certain process. Highlighted things of the verbs may be concrete or abstract. Metaphor can be seen as a concept to understand and experience the other concept and a process of specifying the abstract concept into a concrete concept. For example, he fathered many inventions.

In the above sentence, the word father was used as a verb. This process of converting nouns into verbs underlines our knowledge level of the word "father". In these knowledge levels, it especially highlighted "primitiveness", in other words, it is considered that the abstract domain appear in our cognitive domain through its specific style which we are familiar with.

\subsection{Examples and Analysis}

\subsubsection{Noun}

Nouns are the core factor of biomedical works. Clear statements of experimental materials, experimental methods and experimental results, the precise and appropriate expressions of arguments, the systematic conclusion of the evidence, largely depend on the accurate use of nouns as a premise. Besides, the order of words' appearance is also a reflection of the author's thinking venation. Nouns appeared in materials, methods and results are vivid and specific, while those in the arguments are relatively more abstract and general, they are important parts when one translates those terms. In English biomedical works, one artistic conception is usually expressed by a number of different nouns, while some of the Chinese nouns are different from common translation rules, the application of rhetorical use of nouns also adds literalness to scientific works, and translators 
must provide accurate Chinese translation according to the context and existing medical knowledge.

Case 1: Although the relative contributions of various calcium-regulated processes to neuronal cytoskeleton damage are yet not known, several lines of evidence suggest that over-activation of calpains may play a major role in the pathology of traumatic brain injury (TBI) and cerebral ischemia in vivo.

Translation: 尽管不同钙离子调控的反应过程在神经元细胞股价损伤中的 各种相对作用还不为人知, 一系列的研究证据提示卡配因家族成员的过度激 活在体内创伤性脑损伤和脑缺血的病例发生中起主要作用。

Analysis: The original meaning of the word contribution is "donations", the use of contributions illustrates the function of the reaction process, and declares that neuronal cytoskeleton damage is the result of the combination of several reaction processes which equals to actions, effects and so on. Thus it is translated as “各种作用” by the method of translation.

The form "noun $+s$ " represents the plural form of a noun, while in biomedical scientific English, "proper noun $+s$ " represents a family of a certain material that is constituted by some similar structures and function characters, thus in this case, "calpains" is a calpains family which is currently constituted by several members. And this need to be clearly illustrated when translating, like the word caspases

Case 2: Differences between preclinical and clinical trial outcome with neuroprotective drugs in acute ischemic stroke may be caused by a variety of pitfalls that arise when attempting to extrapolate from animal to human investigation.

Translation: 使用神经保护药物治疗急性缺血性卒中的临床前和临床试验 结果存在差异, 这可能是由于试图将动物实验结果外推导人体研究时产生的 各种潜在的不足引起的。

Analysis: the explanation for pitfall is "the hidden danger, risks, hazards or traps", these explanations are clearly not appropriate to be used here. According to the context, together with some medical knowledge, "pitfall" means the results of animal experiments generated by mechanically experiments are of all kinds like a trap or deficiencies, including "the gap between the design of experiment and measure standard" between these two kinds of research, so it would be more appropriate to translate it into "potential shortage".

\subsubsection{Verbs}

Biomedical works are to reflect the connection between experimenters and experiments, experimental subjects and the results of the experiments, experimenters and the results. These obvious or less obvious connections are often expressed by verbs.

Case 3: Although our own and other laboratories have shown that systemic administration of Calpain Inhibitor II reliably inhibits calpain activation, these studies by themselves do not allow us to conclude that Calpain Inhibitor II attenuated the pathophysiological effects of SAH solely through inhibition of calpain.

Translation: 尽管我们和其它实验室的研究已经表明全身给予卡配因抑制 
剂 II 能可靠抑制卡配因的活性，但不能根据这些实验本身得出卡配因抑制剂 II 可单纯通过抑制卡配因的活性来消弱 SAH 的病理生理作用这一结论。

Analysis: the word "allow" usually refers to "granted or permission", in this sentence, the word "allow" fully reflect the major push that the results have done to the conclusion. This is a concrete manifestation of the relationships between researchers and the research subjects and results during the process of biomedical research. But if you choose "these studies by themselves" as the subject, then the translation may be lack of logic, so we can transfer the object after the word "allow" into a subject of a sentence, while convert the verb after "to" which is a infinitive coupled with "allow" into the predicate of a sentence. Then the translation seems more logic of Chinese habits. Such similar usage words and phrases include permit, lead to conclude and so on.

English biomedical works belong to technological papers. The number of some literature methods such as rhetoric is increasing in recent years, and the flexible use of some vocabulary highlighted the literary connotation of life and science writing. Some of the words can play a role of a single sentence or a group, and this phenomenon reflects the simple and distinctive characteristics of current English biomedical works. And scientific works' combination of scientific nature and literature represents the trend of English biomedical work writing. Translators should try to improve their ability of biomedical research, at the same time, a solid grasp of difficult technical terms' characteristics and an understanding of the key points is also essential.

\subsection{The Influencing Factors of Parts of Speech Shift}

As a kind of mental process, the understanding of parts of speech shift must be based on people's cognitive abilities. To be clearer, our methods of conceiving an object or a scene are very important to understand parts of speech shift. Thus we can see that the influencing factors of part of speech shift types include highlights of things and our perspective of a selected scene.

\subsubsection{The Highlight}

Highlight refers to something that is of major significance or special interest. In cognitive linguistics, different kinds of words reflect different salience. Nouns, for example, have a high degree of highlight, because it refers to spatial domain. Instead, verbs have a low degree of highlights for it refers to the time domain, while spatial domain is more highlighted than the time domain. Generally, high degree of highlighted vocabulary is often converted to a low degree of the highlighted vocabulary. Therefore, nouns being converted into verbs are more common than verbs into nouns.

\subsubsection{Perspective}

Perspectives are also very important in the choice of parts of speech transformation type. It is the formation of an image in a picture plane of a scene viewed from a fixed point and its monopolization. That is to say a starting point is essential when understanding a scene. For example, in the sentence She mothered 
her plants as she does her children, the perspective of the transformed word mother is completely different from the perspective of the word mother in the sentence she took care of her plants in the way she cared for her children.

\section{Biomedical Literature Translation Skills}

\subsection{Types of Transformation of Part of Speech in English}

\subsubsection{Chinese Verbs into Nouns in English}

When at least two or more Chinese verbs appear in a sentence, and these two verbs have a primary and secondary order, the secondary verb in Chinese can be translated into nouns in English.

Case 4: After treatment with energetic ions, either post-formation or during their deposition, these surfaces strongly immobilize proteins and provide a means of cloaking biomaterial surfaces.

Translation: 处理这些具有活性的离子之后, 表面在形成后期或者沉淀形成 期牢固的固定了蛋白质并提供了一种表面隐形的生物材料。

Analysis: In the original English sentence, the word "treatment" is a noun. After translating, it becomes a verb in the Chinese sentence.

Case 5: We now explore the mechanism for the recruitment of a full monolayer of a conformationally stable protein on the ion-treated surfaces and demonstrate that our process creates free radicals, which react with the environment at the surface.

Translation: 我们现在探讨的在离子处理的表面收录一个完整的单层的构 型稳定蛋白质的机制，并证明我们的过程会产生与地表环境反应的自由基。

Analysis: The Chinese verb “收录” is translated into English noun as "recruitment".

Case 6: A quantitative understanding of the interaction of the free radicals with surface-contacting protein molecules is needed to give the control required to form implant surfaces cloaked in patient compatible proteins.

Translation: 提供以控制要求形式植入病人蛋白质表面下的兼容需要对自 由基与表面接触的蛋白质分子之间的互作的一个定量的了解。

Analysis: In the Chinese sentence, “表面接触” belongs to a verb, but it was a noun phrase in the English sentence as "surface-contacting".

Case 7: The presence of two different time constants in the binding process, one for physisorption and one for radical diffusion and covalent binding, is confirmed.

Translation: 在绑定过程中存在两个时间常数, 一个是物理吸附, 一个是激 进的扩散和共价结合的假设得到了验证。

Analysis: The Chinese verb “存在” is translated as an English noun "presence".

\subsubsection{Verbs in Chinese Translated into English Adjectives}

When verbs in Chinese are used to express one's perception, emotion, mental state, and also a situation for a long time, in accordance with the English language rules, the above words usually appear in English as adjectives. And when 
the set structures of verbs mean to describe states appear, they also need to be translated into adjective.

Case 8: SDS is an ionic surfactant that unfolds proteins and disrupts the forces responsible for physisorption, while leaving the covalent bonds intact.

Translation: SDS 是一种能够展开蛋白质和打破用于物理吸附的力同时使共 价键完好无损的离子表面活性剂。

Analysis: “用” is a verb in the Chinese sentence, while its translated word is "responsible" and it is an adjective.

\subsubsection{Chinese Verbs into English Prepositions or Prepositional Phrase}

In the following circumstances, verbs in Chinese can be translated into prepositions in English. First, when there are several paratactic structures in a sentence at the same time, one of them can be translated into preposition phrases. Second, some prepositions evolved from verbs, and this verb can be replaced by a preposition. Third, when several verbs appear in one sentence and the verb works as an adverbial modifier, when this verb can be translated into a proposition.

Case 9: By developing a form of high-quality micro-structured optical elements, improved imaging of malignancies and of treatment monitoring can be achieved.

Translation: 通过开发一种高质量的微结构化光元素, 改良的恶性肿瘤成像 技术和治疗监测是可以实现的。

Analysis: The word "by" is a preposition in the English sentence and it can be translated as a verb in Chinese.

\subsubsection{Chinese Adjectives, Adverbs Being Translated into English Nouns} In order to meet the needs of rhetoric and grammar, some adjectives and adverbial words in Chinese can be translated into English nouns.

Case 10: The ability to covalently immobilize onto a hydrophilic surface is a key advance that allows the retention of protein conformation and bioactivity.

Translation: 能够共价固定到一个亲水表面是一个关键的进展, 这一能力允 许保留蛋白质构象和生物活性。

Analysis: “能够” is an adjective in the Chinese sentence while it is a noun in the translated English sentence.

\subsection{Give Priority to Word-for-Word Translation, Together with a Paraphrase}

Biomedical literature translation belongs to the scientific and technological translation category. No one would confuse it with literature art. Scientific and technological translation methods can be broadly divided into "literal translation" and "free translation". Generally, scientific translation would choose a literal translation.

As mentioned above, practically, if you can make the translated version in accordance with the original both in structure and content, we should definitely stick to a literal translation. But sometimes, it is allowed and promoted to try a free translation as well, because the difference of English and Chinese expression 
is very evident. Once someone take care of the words and expressions in the text, it would be difficult to be accurate and smooth to reproduce the ideological content of the original. Then we should try to adjust the original expression at this moment, use the technique of free translation as a supplement.

The translated structure and expression would be quite different from the original when one adopts a liberal translation, but they can be clear and specific. Taken this into account, therefore, when one face difficult to perfectly express the original content, it would be better to try a free translation instead.

\subsection{Accurate Translation}

In biological medical literature translation work, one must be careful so as not to misunderstand the technical term as an ordinary word which does mean something professional. At the same time, one should not take an ordinary word as something special. The word "satellite", for example, non-professional person will often translate it as “卫星”, while its biomedical meaning is “随体”, it is one part of the chromosome form. “DNA chip” translated as “DNA 芯片”. “coning” translated into “重叠群”, “clone cloning” translated as “克隆连续序列法”.

Due to the rapid development of science and technology in the world, new subjects, new concepts, new theories and new methods constantly emerges, accordingly, a large number of new scientific and technological terms come into being, such as "symmetry" translated as “同线性”, meanwhile, there are also a large number of biological terms abbreviations such as McAb for mono-clonalantibody, ALV for avian-leukosis-virus and so on. Therefore, we should pay more attention on the translation of technical terms.

\subsection{The Analysis of Deep Structure}

Analysis is a means of understanding the original text. When we translate a sentence, we must first analyze the sentence structure and find out the relationship between the words and sentences, then words and sentences can be expressed by the correct understanding of the original content. The meaning of a sentence can be roughly divided into the following three levels, restrict lexical meaning, grammatical relationship and these relations, incorrect translation is just a patchwork of lexical meanings. Scientific and technological works contain so many difficult sentences, so we must be meticulous when processing them so as to avoid mistakes. What's more, the content often appears with different sorts of numbers, data, formulas, equations, molecular formula, and all kinds of signs, symbols, graphics and so on, all of which must be accurate in the translation. Therefore, translators must cultivate and carry forward the rigorous attitude with the translation work of science and technology books and papers, in order to avoid scientific research mistake or production losses caused by careless translation.

\section{Conclusion}

Parts of speech shift are one of the most commonly used techniques in Eng- 
lish-Chinese translation. We should try to shift the part of speech flexibly, in order to achieve a vivid translation effect. As a matter of fact, we can almost see all parts of speech shifts in biomedical works. This kind of phenomenon is very common and very flexible in today's translation work.

Through this research and analysis, we should learn to master the essence of shifting part of speech in order to draw inferences about other cases from one instance. Meanwhile, we should establish a set of good translation guidelines on the foundation of cultivating the awareness of shifting part of speech. We must try to avoid mechanical translation and obey the original syntax blindly; instead, we should decide whether to use the method of shifting part of speech according to the logical relationships and expressions of the text. Only in this way can we make those complex sentences easy to understand and express the original theme smoothly and accurately. As long as one can master language transformation rules, and apply it in practice, the translation can achieve an unexpected effect.

\section{Acknowledgements}

This paper is supported by Project of Education, Science and Research of Shandong Province (No. 15SC105), and Social Science Project of Shandong Agricultural University (No. 23899).

\section{References}

Anderson, J. M., \& Marchant, R. E. (2015). Biomaterials: Factors Favoring Colonization and Infection. Infections Associated with Indwelling Medical Devices, Waldvogel and AL Bisno (3rd ed., pp. 200-205). Washington DC: ASM Press.

Bassnett, S. (1998). The Translation Turn in Culture Studies. In: S. Bassnett, \& A. Lefevere, Eds., Construction Cultures (pp. 123-140, 138-139). Clevedon: Multi Lingual Matters Ltd.

Caffarel, A. (2010). Systemic Functional Grammar and the Study of Meaning. In H. Narrog, \& B. Heine (Eds.), The Oxford Handbook of Linguistic Analysis (pp. 797-825). Oxford: Oxford University Press.

Cai, J. G. (2012). Academic English: Needs Analysis and Teaching Methods. Foreign Language Learning Theory and Practice, No. 2, 30-35.

Cook, G. (2010). Translation in Language Teaching: An Argument for Reassessment. Oxford: Oxford University Press.

Dancygier, B. (2012). Viewpoint in Language: A Multimodal Perspective. Cambridge: Cambridge University Press. https://doi.org/10.1017/CBO9781139084727

Gentzler, E. (2001). Contemporary Translation Theories (p. 187, 203). Clevedon: Multi Lingual Matters Ltd.

Gu, Z. Z. (2012). Research on ESP Ecologic Environment-A Case Study at AUFE. Computer-Assisted Foreign Language Education, No. 148, 47-59.

Kong, F. X. (2012). The Study of Implicit and Explicit Learning on the EGP and ESP. Modern Educational Technology, 22, 74-78.

Nida, E. (2001). Context in Translation (p. 1, 3, 108-113, 109, 111, 108-109). Amsterdam: John Benjamins Publishing Co.

Sarceive, S. (1994). Translation and the Law: An Interdisciplinary Approach. In: M. 
Snell-Hornby, F. Pöchhacker, \& K. Kaindl (Eds.), Translation Studies: An Inter-Discipline (pp. 302-305). John Benjamins Publishing Co., Amsterdam.

Shi, W. N. (2014). Comparison on ESP and EGP Learning Anxiety. Journal of Fuyang Teachers College (Social Science), No. 1, 141-143.

Snell-Hornby, M. (2006) The Turns of Translation Studies: New Paradigm or Shifting Viewpoints (p. 104). Amsterdam: John Benjamins Publishing Co.

https://doi.org/10.1075/btl.66

Submit or recommend next manuscript to SCIRP and we will provide best service for you:

Accepting pre-submission inquiries through Email, Facebook, LinkedIn, Twitter, etc. A wide selection of journals (inclusive of 9 subjects, more than 200 journals)

Providing 24-hour high-quality service

User-friendly online submission system

Fair and swift peer-review system

Efficient typesetting and proofreading procedure

Display of the result of downloads and visits, as well as the number of cited articles Maximum dissemination of your research work

Submit your manuscript at: http://papersubmission.scirp.org/

Or contact ojml@scirp.org 